\title{
A PEDAGOGIA DA RETOMADA: decolonização de saberes
}

\author{
PIMENTEL DA SILVA ${ }^{1}$, Maria do Socorro \\ Universidade Federal de Goiás (UFG)
}

\section{RESUMO}

O presente texto chama a atenção para a importância de se construir bases epistêmicas necessárias para superar as amarras da colonialidade do saber. Mostra, também, como essas bases estão sendo construídas no diálogo entre pesquisadores indígenas e não indígenas situados no Núcleo Takinahakỹ de Formação Superior Indígena da Universidade Federal de Goiás. Esta é a construção da pedagogia da retomada, que traz para o debate os saberes indígenas silenciados, colocando-os em movimentos em articulações intra e interculturais.

Palavras-chave: Retomada. Epistemologia. Indígenas. Temas Contextuais.

\section{ABSTRACT}

The present text draws attention to the importance of building epistemic bases necessary to overcome the bonds of the coloniality of knowledge. It also shows how these bases are being built in the dialogue between indigenous and non-indigenous researchers located in the Takinahaky Nucleus of Indigenous Higher Education of the Federal University of Goiás. This is the construction of the pedagogy of the recovery, which brings to the debate the knowledge Indigenous peoples, placing them in movements in intra and intercultural articulations.

Key words: Revival. Epistemology. Indigenous. Contextual Themes.

\section{INTRODUÇÃO}

De acordo com meus estudos e com minha experiência em cursos de formação de professores indígenas em várias regiões do Brasil, a busca dos indígenas pela educação libertadora constitui-se

1 Professora Associada do Núcleo Takinahakỹ de Formação Superior Indígena da Universidade Federal de Goiás. Coordenadora Geral da Ação 'Saberes Indígenas na Escola' da Rede UFG/UFT/UFMA. 
fundamentalmente a partir de quatro perspectivas: (1) Acesso aos saberes tradicionais indígenas; (2) Acesso aos conhecimentos não indígenas; (3) Articulação entre diversos saberes; e (4) Produção de bases epistêmicas interculturais para fundamentar as práticas pedagógicas.

Nessa percepção, a educação situa-se, prioritariamente, nos direitos dos povos indígenas, na vivência cultural; na consideração do saber dos anciãos e das anciãs; no cuidado com as crianças e com os jovens; na inclusão de projetos sociais/comunitários; na qualidade de vida; na proteção de rios, lagos e lagoas; na proteção do território e de suas riquezas; na proteção das árvores etc. Tem-se, assim, a prática de uma educação ambiental de abordagem sociohistórica, o que equivale dizer, uma educação para manejos de mundos.

Este tipo de educação revê valores e busca alternativa frente ao modelo hegemônico vigente em nosso país. Ou seja, leva em consideração os aspectos ecológicos, sociais, econômicos, políticos, culturais, epistêmicos e linguísticos. A partir dessas ideias, é possível propor mudanças pedagógicas, transformando a prática educativa em uma ação efetiva para que o ensino consiga transpor as dimensões do espaço escolar, possibilitando uma articulação, tanto com a cosmovisão de cada povo indígena quanto com as demandas contemporâneas advindas da vida intercultural.

Para dar conta desse desafio, torna-se necessária a construção de práticas pedagógicas fundadas em perspectivas inovadoras de congregação de todos/as envolvidos/as nos processos de retomada de valores e saberes. Exige-se, ainda, a elaboração de novos conhecimentos que se expressam em ideias, conceitos, paradigmas imprescindíveis à construção de matrizes epistêmicas interculturais, orientadas para o enfrentamento de estruturas de educação governadas pelas concepções: monolíngue, monocultural e disciplinar.

Um dos riscos que se corre na educação disciplinar é o desaparecimento de mais conhecimentos indígenas. É nisto que situa a reflexão de Lariwana (2011)

Percebi na minha pesquisa que a minha língua indígena serviu na escola apenas como um instrumento facilitador da língua portuguesa. Até hoje alguns professores estão nessa gaiola, ao invés de procurar pesquisar a realidade que envolve o mundo das crianças e também dos adultos e mostrar o valor da nossa cultura. Estamos 
buscando dentro dos livros didáticos que são entregues pela secretaria de educação educar nossos alunos sem discutir. Desta forma, os nossos conhecimentos tradicionais são inferiorizados.

Muitas são as investigações que reconhecem a necessidade de mudanças das práticas pedagógicas nas escolas indígenas, mas poucas são aquelas que, para além da denúncia, apresentam alternativas concretas que proponham a superação dessa injustiça histórica, apontada pelo pesquisador citado acima. As palavras do estudioso revelam que a cultura indígena está na escola apenas porque o/a aluno/a e o/a professor/a são indígenas, mas passam despercebidos/as, em função do predomínio dos saberes ocidentais, na maioria das vezes.

Nesta direção, Candau (2010, p. 14) argumenta chamando a atenção da rigidez escolar. Para ela:

[...] toda a rigidez de que se reveste em geral a organização e a dinâmica pedagógicas escolares, assim como o caráter monocultural da cultura escolar precisam ser fortemente questionados. Devem ser enfatizadas a dinamicidade, a flexibilidade, a diversificação, as diferentes leituras de um mesmo fenômeno, as diversas formas de expressão, o debate e a construção de uma perspectiva crítica plural.

Na percepção rígida, a escola perde a ideia de ser um espaço cultural, fronteiriço, de intercâmbios, características importantes da educação intercultural, vista, assim, por Fleuri (2003, p. 31):

[...] é sob esta perspectiva que a educação intercultural se preocupa com as relações entre os seres humanos culturalmente diferentes uns dos outros. Não apenas na busca de apreender o caráter de várias culturas, mas sobretudo na busca de compreender os sentidos que suas ações assumem no contexto de seus respectivos padrões culturais e na disponibilidade de se deixar interpelar pelos sentidos de tais ações e pelos significados constituídos por tais contextos. 
Uma prática pedagógica organizada nos princípios da interculturalidade precisa ter dinâmica própria, que lhe permita $o$ exercício do pensamento crítico, e que conduza a uma visão política de cidadania, capaz de integrar saberes, valores, propiciando, assim, a recuperação da autonomia dos sujeitos e de sua ocupação no mundo, de forma libertadora, como defende Freire (2001).

Para este estudioso, a libertação intelectual só será possível mediante a uma educação libertadora, aquela que se opõe à colonialidade do poder e do saber. Ele propõe, desse modo, o abandono à educação bancária, a qual transforma os seres humanos em "recipientes", a serem "preenchidos", ou seja, uma educação da desalienação e da problematização. Este tipo de educação rompe com a concepção dualista e hierarquizada que sustenta a visão ocidental, europeia e cristã de mundo e que perpassa os processos de ensino e aprendizagem da sociedade não indígena brasileira, chegando, também, às escolas indígenas.

Essas reflexões contribuíram com a construção da pedagogia da retomada. Nesta, emerge a necessidade de repensar a escola em todas as suas dimensões, desde sua raiz epistemológica até as práticas pedagógicas cotidianas, e a vitalidades dos lugares epistêmicos e o protagonismo indígena.

\section{Pedagogia da retomada: um debate necessário}

A pedagogia da retomada é gestada nas matrizes culturais indígenas. Fundamenta-se nos estudos feitos pelos indígenas durante as práticas pedagógicas de estágio e das pesquisas dos projetos extraescolares ${ }^{2}$; do Curso de Licenciatura em Educação Intercultural ${ }^{3}$; durante a construção dos projetos políticos pedagógicos do Curso de Especialização em Educação Intercultural: Gestão Pedagógica; e das pesquisas da Ação 'Saberes Indígenas na Escola', que se realiza exercendo três papeis: formação continuada de professores/ as, pesquisa e extensão, contando com a orientação dos sábios/as indígenas e das universidades envolvidas.

2 Estágio e Projetos Extraescolares são ações do Curso de Educação Intercultural da UFG. Uma de caráter pedagógico e a outra, de pesquisa e documentação de saberes indígenas, tendo como línguas oficiais, as indígenas.

3 Os cursos de licenciatura e de especialização são da Universidade Federal de Goiás. 
Toda sustentação da pedagogia da retomada vem dessas fontes, mas também de estudos feitos em outros contextos e por pesquisadores contrários à monocultura do saber, como, por exemplo, os defendidos por Santos (2004). Este estudioso reconhece que todo o conhecimento é situado, portanto, parcial e limitado. Esta postura não é reconhecida pela ciência, a qual promove uma visão e um projeto de mundo que desconsidera os outros conhecimentos presentes no planeta, em nome do saber chamado de científico. Um projeto que rompeu, violou, explorou e invisibilizou diferentes modos de vida. Por isso, Santos chama a atenção para a importância de restituir às ciências a sua espessura cultural e histórica.

A pedagogia da retomada problematiza a questão trazendo para o debate a espessura da diversidade epistêmica do mundo, que segundo (SANTOS, 2004: 46), "é potencialmente infinita, pois todos os conhecimentos são contextuais. Não há nem conhecimentos puros, nem conhecimentos completos; há constelações de conhecimentos".

Esta noção dialoga firmemente com a ideia de Temas Contextuais, que, segundo Pimentel da Silva (2012), favorece a retomada de saberes apagados, escondidos em muitas memórias de sábios, perdidos entre gerações. Para a autora, o Tema Contextual é

\begin{abstract}
(...) a contextualização do conhecimento sem hierarquia das disciplinas, mas principalmente sem a hierarquia da colonialidade do saber. Ou seja, é o entendimento de que o conhecimento está em todos os lugares onde os diferentes povos e suas culturas se desenvolvem e, assim, são múltiplas as epistemes com seus muitos mundos de vida. Há, assim, uma diversidade epistêmica, que comporta todo o patrimônio da humanidade acerca da vida, das flores, do sol, das árvores, das águas, dos animais, das aves, dos insetos, da terra, do céu, das estrelas, do fogo, dos minerais, do ar, da arquitetura, dos homens, das mulheres etc. Não importa o nome da Ciência na qual esses saberes estão vinculados, se Física, Biologia, Matemática, Geografia, História, Química etc. (PIMENTEL DA SILVA, 2012a, p. 22).
\end{abstract}

Há vários tipos de temas contextuais:intraculturais, interculturais, e, até mesmo, transculturais. Os interculturais potencializam-se pela articulação de saberes distintos, em sua natureza e contextos, e pelo 
bilinguismo epistêmico, que, segundo Pimentel da Silva (2016), não se refere apenas às línguas, mas também aos saberes. Muitos temas, ao se espraiarem, tornam-se transculturais, graças ao rompimento das fronteiras epistêmicas. Neste entrelugar, a aprendizagem deve ser facilitada e exercitada em formas diversas para permitir a criação de conhecimentos que se atrelem ao existir humano, a existência enquanto devir.

Neste sentido, é importante reconhecer o outro não apenas como igual em direitos, mas como complementar. Um ser humano precisa de outro ser humano sempre. Todo saber precisa de outro saber, pois não há saberes completos. $\mathrm{O}$ reconhecimento da reciprocidade cria uma solidariedade entre os complementares.

Quando os temas contextuais estão situados em bases epistêmicas intraculturais, reivindicam as línguas indígenas. Muitos temas desses sequer têm como serem traduzidos: muitos são sagrados; outros são segredos. Alguns são corrompidos, quando traduzidos. Nestas realidades, a articulação dos saberes reside no campo do sagrado, do familiar, do segredo, mas também no campo da arte, do esporte, da música, e da relação cultura e natureza. Quando os temas são de pertencimento cultural, promovem diálogo entre as vozes presentes, que resgatam, amigavelmente, as ausentes, vitalizando, assim, os saberes milenares nesse movimento pedagógico.

Os temas contextuais que favorecem a articulação entre a cultura e a natureza tratam dessas realidades como um patrimônio. Os povos indígenas sempre afirmam que é da natureza que vêm todos os elementos para educar seus filhos. Mawederu Karajá (2009), em suas reflexões sobre a natureza, afirma que sem os pés de buriti não haverá a wèrirí (cesta/bolsa feita do olho da palha do buriti).

É por meio da feitura dessa cesta que meninas Karajá aprendem, além de tecê-la, muitos outros conhecimentos, todos necessários à formação feminina. É por isso que Pimentel da Silva (2001) afirma que, quando uma criança está aprendendo a fazer uma peça de artesanato, ela vive uma experiência de multicoletividades de saberes, carregada de valores e significações, que ela registra em sua memória, através desse aprendizado.

O aprendizado é um processo contínuo no vivido. É assim que surgem sujeitos novos, em práticas tradicionais, como, por exemplo, o "cacique da cultura", uma função criada pelos Karajá de algumas aldeias, para movimentar as tradições culturais. Ressurgem também, nas novas práticas culturais, sujeitos tradicionais. Neste movimento, 
"passado-presente" torna-se parte da necessidade, e não da nostalgia, de viver (BHABHA, 2013, p. 28 - 29).

Recentemente, um Karajá, aluno do Curso de Educação Intercultural da UFG, sabendo da existência do livro Linguagem especializada: mitologia Karajá ${ }^{4}$, composto de dez Ijky (Histórias), quis adquiri-lo com a intenção de conhecer essas histórias. Dei-lhe um exemplar. Dias depois, ele me ligou e me contou que leu algumas Ijky para sua avó, e esta ficou muito feliz e entusiasmada, tendo ainda contado para ele outras.

O mesmo Karajáleu algumas delas para seus filhos, que ficaram curiosos e queriam saber mais dos fatos narrados. Adormeceram com o pai contando as histórias. Este pai, que ainda é muito jovem, quer conhecer muitas outras histórias de seu povo. Um conhecimento que não aprendeu quando pequeno, mas que agora deseja adquirir. Um exemplo de práticas novas, a de ler histórias escritas em inyrybè (fala iny), formando um novo Ijkydu (historiador). Ou seja, a prática tradicional de contar histórias para os filhos e netos retornando por meio da escrita.

O movimento da retomada epistêmica vem encantando os indígenas por muitas razões, entre elas: (1) O acesso a certos saberes tradicionais que muitos não conhecem ou que conhecem pouco, ou, ainda, apenas ouviram falar. Um Akwê-Xerente me disse: "estou aprendendo tanto saberes do meu povo que eu nem sabia que existia."; (2) A descoberta de que os paradigmas inovadores da dita ciência ocidental moderna, como, por exemplo, a da visão quântica, que reconhece que todos os seres existentes no planeta estão conectados, são interdependentes, não são novidades para os indígenas, pois este sempre fora o jeito de pensar desses povos, como bem expressou um ancião Apinajé: "Nada está só no mundo".

O chão da escola indígena, portanto, deve ser a conectividade, e não a disciplinaridade. A escola precisa ter o que Paulo Freire chama de "feições de beleza", que, no meu entender, deve ter também feições de afeto, de aproximação, de alegria. A alegria precisa ser liberada, conforme afirmou o professor Matalòri Karajá. Este tipo de educação desperta, sem sombra de dúvida, uma imensa força de sabedoria e de amor no coração das crianças, dos adultos e de todos que estiverem envolvidos nesse processo.

4 Pimentel da Silva, M. do S.; Rocha, L. M. (Orgs.). Linguagem especializada: mitologia Karajá. Goiânia: Editora UCG, 2006. 
Percebe-se, assim, que a abordagem da pedagogia da retomada percorre diferentes trilhas. Abarca em seu percurso debates críticos sobre a superação da reprodução de saberes, e da passividade pedagógica. Traz, em seu destino, a incessante busca por paradigmas inovadores, a partir dos quais se promovem a interconexão de saberes, rompendo com o padrão pedagógico que fragmenta e compartimenta conhecimentos entre as disciplinas, desconsiderando as realidades complexas, e impossibilitando ao aluno apreender "o que é tecido junto", segundo Morin (2008:13-14).

É nesse sentido que Manaijè Karajá (2014) reivindica uma escola intercultural e transdisciplinar, pois, segundo ele, dentro da interculturalidade e da transdisciplinaridade, colocam-se desenhos, músicas, artes, pintura etc. Ideia reforçada por Dodani Krahô, durante o encontro da Ação 'Saberes Indígenas na Escola', na aldeia São José, do povo Krikati, no estado do Maranhão, ao afirmar: "para que os saberes indígenas não sumam, é preciso movimentá-los, pois os saberes não estão mortos, mas precisam de movimentos. $\vec{E}$ bonito falar a nossa linguagem, é bonito se pintar, é bonito cantar as músicas de nosso povo."

Resistir e inovar na área da produção do conhecimento necessário ao ensino escolar é o grande movimento dos/as pesquisadores/as indígenas da Ação 'Saberes Indígenas na Escola'. Para eles/elas, um/uma cantor/a é um/uma pesquisador/a, pois ele/ ela está buscando esse saber. Ele/ela quer ter esse saber. O mesmo acontece com uma pessoa que está se tornando um/uma artesã/ artesão. São pessoas novas buscando com os homens e as mulheres de sabedorias esses conhecimentos. Este é o sentido de ser pesquisador/a indígena na retomada do patrimônio cultural. Um movimento bonito e interessante de enfrentamento à colonialidade do saber.

Durante a reunião da Ação 'Saberes Indígenas na Escola', realizada na Aldeia Quieta, município de Amarantes, no estado do Maranhão, as professoras pesquisadoras Tenetehar deram vários depoimentos do efeito positivo das pesquisas em suas vidas. Um depoimento de uma professora me chamou muita atenção. Essa professora não aprendeu a falar a língua Tenetehar e nunca questionou por que isso aconteceu. Os mais velhos de sua família sabem essa língua, mas não a usam.

A partir das pesquisas, a referida professora resolveu aprender tudo aquilo que não lhe fora ensinado quando criança. Está promovendo uma revolução cultural em sua comunidade. Conseguiu realizar até rituais, com ajuda de quem sabe fazê-lo. É grande 
seu entusiasmo em levar os saberes Tenetehar aprendidos em sua pesquisa para a escola.

É assim que novas percepções e experimentações pedagógicas surgem no interior das escolas, de modo a combater a pedagogia da reprodução, aquela que opera seguindo modelos e ideais que poucos servem à vida, e à defesa do território indígena, por exemplo. Não problematiza a realidade em que vive a maioria dos indígenas. Ameaçados, com seus territórios invadidos, com suas terras não demarcadas, com expansão da fronteira agrícola e com os interesses de empresas nacionais e multinacionais pelas riquezas existentes nos territórios indígenas.

Essas questões não são colocadas no currículo oficial dos estados, imposto às escolas indígenas. Neste sentido, Iolò (2016) afirma que: "o ensino implantado na escola afasta as crianças da musicalidade Karajá e das tradições. ". O resultado disso, conforme Iakymytywygy (2016), é que os jovens não procuram os mais velhos para se atualizarem.

Nessa linha argumentativa, é necessário que a composição curricular leve em conta os conhecimentos oriundos das matrizes culturais indígenas, mas também da matriz da cientificidade, além da matriz articulação dos conhecimentos, formando, assim, uma rede onde todas as formas de conhecimento têm valor. A matriz intercultural considera os diferentes modos de produção de saberes. Questiona o modelo canônico científico ocidental, um modelo que desconsidera a pluralidade de conhecimentos produzidos em diversos lugares do planeta.

$\mathrm{Na}$ contramão desse movimento canônico, surge a noção da pedagogia da retomada, entendida por Manaijè (2015), como um movimento do renascimento cultural. Ou seja, a retomada é um movimento de descolonização dos saberes indígenas. Um movimento necessário para o diálogo intercultural crítico, que, nas palavras de Tubino (2005), aponta para a construção de sociedades que assumam as diferenças e as especificidades. O autor esclarece que esta é diferente da interculturalidade funcional.

A interculturalidade funcional representa o discurso oficial dos estados como estratégia para favorecer a coesão social, sem questionar as causas da assimetria social e cultural. Neste sentido, o interculturalismo funcional visa diminuir os conflitos entre povos e movimentos sociais, sem afetar a estrutura e as relações de poder vigentes. Dessa forma, a interculturalidade é assumida como 
estratégia para favorecer os grupos minoritários subalternizados a assimilar a cultura hegemônica, como um bem de conquista.

É por isso que estudiosos como Mignolo (2003) e Walsh (2009) afirmam que descolonizar significa, entre outras coisas, aprender a desaprender. Para Grosfoguel (2009) a descolonização epistemológica tem de partir de lugares subalternos. O autor destaca que isso é necessário, porque os paradigmas epistemológicos hegemônicos têm um cânone restrito de pensamento e um ponto de vista universalista. É por isso que vale a pena investir em um projeto político pedagógico, já que investir no projeto atual, neoliberal, monolíngue e monocultural é fomentar a continuação de um ideal calcado apenas no pensamento Ocidental.

\section{ALGUMAS CONSIDERAÇÕES}

Para que seja possível a promoção da educação intercultural, faz-se necessária a existência, entre outras medidas, de novos arcabouços teóricos, capazes de trazer para essa construção, os saberes indígenas, que estão, segundo Santos (2009), "do outro lado da linha", inferiorizados, silenciados, e apagados. O autor esclarece que o pensamento hegemônico da modernidade ocidental europeia é um pensamento abissal que coloca linhas divisórias entre dois universos: "deste lado da linha", o Ocidente europeu; e "do outro lado da linha”, a zona colonizada, que é a inexistência, a falta de humanidade.

Por isso, é muito importante refletir sobre como os saberes indígenas estão entrando nas escolas. Na maioria das vezes, entram como conteúdos disciplinares ou de uma disciplina, como, por exemplo, 'Arte e Cultura'. Neste contexto, surge a seguinte pergunta: Por que apelidar esses saberes? Os saberes indígenas têm nome, mas com certeza, não são chamados de geografia, biologia, física, muito menos de científicos. Se assim os chamassem, qual seria a razão de discutir diversidade, interculturalidade, transdisciplinaridade? Neste sentido, vale a apena questionar se as respostas procuradas para os problemas enfrentados pelos povos indígenas são as mesmas encontradas para solucionar os problemas do mundo ocidental moderno. Diversidade é diversidade em todo seu contexto. Não é mesmo?

Tenho percebido em quase todo o Brasil a insatisfação dos/as professores/as indígenas com a escola que eles/elas têm. Uma escola 
que não acompanha o manejo de mundo desse povo. Uma escola que ainda está do lado de fora. Tudo depende de aprovação externa, ou seja, do não índio. Talvez seja por isso que não conheço nenhum indígena feliz com a escola que tem.

Os estudos em andamento pelos pesquisadores da Ação 'Saberes Indígenas na Escola' trazem em suas descobertas inovação de paradigmas. Essas referências colocam em destaque a pluralidade de saberes, evidenciando-se a busca de bases epistêmicas, necessárias ao desenvolvimento de educação escolar indígena em perspectivas interculturais, focalizando, neste contexto, a importância de reconhecer saberes indígenas historicamente silenciados.

As riquezas epistêmicas movimentadas durante a construção dos projetos políticos pedagógicos, no curso de especialização, proporcionaram momentos de reflexão coletiva, dos quais originaram elementos para a produção da noção da pedagogia da retomada. Esta estabelece outra imagem de pensamento pedagógico que suscita uma maior liberdade às experiências culturais e interculturais.

O desafio em trilhar os caminhos encontrados é grande, mas eles foram achados e estão sendo construídos/reconstruídos, e que eles possam fluir e se ramificar diversas experiências educativas escolares e comunitárias, e na articulação dessas duas agências, um destino melhor para a educação escolar indígena. Nesse caminhar, primeiro, há de se desconstruir o que foi enraizado pela colonialidade do saber, esvaziar o que enche nossas mentes, para nos disponibilizarmos a aceitar a diferença em um grande abraço humano, e em produções de solidariedade.

\section{REFERÊNCIAS}

BHABHA, Homi K. O local da cultura. 2 ${ }^{\mathrm{a}}$ ed. Belo Horizonte: UFMG, 2013.

CANDAU, Vera Maria (org.). Reinventar a Escola. Petrópolis, RJ: Vozes, 2010.

FREIRE, Paulo. Educação como prática da liberdade. $25^{\mathrm{a}}$ ed. São Paulo: Paz e Terra, 2001.

FLEURI, R. M. Intercultura e educação. Revista Brasileira de Educação, Santa Catarina: Universidade Federal de Santa Catarina, Centro de Ciências da Educação, 2003. Disponível em: <http://www. scielo.br/pdf/rbedu/n23/ n23a02. Acesso em: 01 jul. 2015. 
GROSFOGUEL, Ramón. (2009) "Para descolonizar os estudos de economia política e os estudos pós-coloniais: transmodernidade, pensamento de fronteira e colonialidade global" in B. S. Santos \& M. P. Meneses (orgs.), Epistemologias do sul, Coimbra, Almedina.

JAVAÈ, Iólò. Relatório da Especialização em Educação Intercultural e Transdisciplinar: Gestão Pedagógica. Goiânia: UFG/Núcleo Takinahakỹ de Formação Superior Indígena, 2016.

IAKYMYTYWYGY, Cleberson Tapirapé. Relatório da Especialização em Educação Intercultural e Transdisciplinar: Gestão Pedagógica. Goiânia: UFG/Núcleo Takinahakỹ de Formação Superior Indígena, 2016.

KARAJÁ, Mawederu. Caderno de Estágio. Goiânia: UFG/Núcleo Takinahakỹ de Formação Superior de Professores Indígenas/Curso de Educação Intercultural, 2010.

KARAJÁ, Manaijé. Relatório da III Reunião da Ação 'Saberes Indígenas na Escola'. Goiânia: UFG/Núcleo Takinahakỹ de Formação Superior Indígena, 2014.

KARAJÁ, Manaijè. Relatório da IV Reunião da Ação 'Saberes Indígenas na Escola'. Goiânia: UFG/Núcleo Takinahakỹ de Formação Superior Indígena, 2015.

LARIWANA, L. Caderno de Estágio. Goiânia: UFG/Núcleo Takinahakỹ de FormaçãoSuperior de Professores Indígenas/Curso de Educação Intercultural, 2011.

MIGNOLO, W. D. Histórias locais/projetos globais. Colonialidade, saberes subalternos e pensamento liminar. Tradução de Solange Ribeiro de Oliveira. Belo Horizonte: Editora UFMG, 2003.

MORIN, Edgar. Da necessidade de um pensamento complexo. Trad. Juremir Machado da Silva. Para navegar no século XXI - Tecnologias do Imaginário e Cibercultura, 2008, p. 1-27.

PIMENTEL DA SILVA, M. do. S. A função Social do Mito na Revitalização da Língua e da Cultura Karajá. Tese de Doutorado. PUC, São Paulo, 2001.

Texto inédito,

. A pedagogia da contextualização intracultural e intercultural.

2012.

. Possíveis caminhos para a autonomia da educação escolar indígena. PIMENTEL DA SILVA, M. do. S.; NAZÁRIO, M. de. L.; DUNCK 
CINTRA, E. M. In: Diversidade cultural indigena brasileira e reflexões no contexto da educação básica. Goiânia: Editora Espaço Acadêmico, 2016.

SANTOS, B. S. MENESES, M. P.; NUNES. J. A. Introdução: para ampliar o cânone da ciência: a diversidade epistemológica do mundo”. In: . (org.). Semear outras soluções: os caminhos da biodiversidade e dos conhecimentos rivais. Porto: Afrontamento, 2004.

SANTOS, Boaventura de Sousa. "Para além do pensamento abissal. Das linhas globais a uma ecologia de saberes". SANTOS, B. S. e MENEZES, M. P. Epistemologias do Sul. Coimbra: Almedina, 2009.

WALSH, C. Interculturalidade Crítica e Pedagogia Decolonial: in-surgir, re-existir e reviver. In: CANDAU, V. M. (Org.). Educação Intercultural na América Latina: entre concepções, tensões e propostas. Rio de Janeiro: 7 Letras, 2009. 
